\title{
Medical records, patient privacy and the control of information
}

by Joan Loughrey

$\mathrm{T}$ he use of patient data by the NHS raises significant implications for patient privacy, particularly in the light of developments such as the automation of patient data and genetic databases. Patient information may be sought for a broad range of purposes ranging from education and research to administration and clinical audit. The privacy of patient information is protected both by the common law action for breach of confidence and by the data protection legislation. This article will focus on how successful the former is in protecting privacy by assessing the extent to which it facilitates the control by patients over the use and disclosure of personal information.

Since the incorporation of the European Convention on Human Rights into UK law, the action for breach of confidence has been subject to rapid development to accommodate Article 8 privacy rights. Whereas previously it was unclear whether damages could be awarded for distress alone, a recent decision of the Court of Appeal did award such damages against a doctor, affirming the decision of the judge at first instance that to fail to do so would deprive a complainant of an adequate remedy and thus breach her Article 8 rights (Cornelius $v$ de Taranto [2002] EMLR 6 affirming [2001] EMLR 12 at [65]-[77]). As a result, the action for breach of confidence has the potential to provide a significant remedy for misuse of patient information. Despite this, it can be argued that it currently provides inadequate protection for patient privacy. There are two reasons for this.

Firstly, although it is sometimes argued that the purpose of the law of confidentiality is to protect patient autonomy by protecting patients' ability to exercise control over personal information, it will be seen that the common law has failed to grant patients effective control over the use and disclosure of their medical records (see for example, G Phillipson, H Fenwick, "Breach of Confidence as a Privacy Remedy in the Human Rights Act Era" (2000) 63 MLR 660; I Kennedy "The Doctor, the Pill and the Fifteen Year Old Girl", in I Kennedy (ed.) Treat Me Right (Oxford: Clarendon, 1989) p 113). Secondly recent legislative developments in the form of section 60 of the Health and Social Care Act 2001 and the Health Service (Control of
Patient Information) Regulations 2002 have reduced such control as had been permitted and restricted the scope of the common law.

In theory the common law permits patients to control information by requiring that their consent is obtained before it is used. If a patient consents either expressly or impliedly to the release of information there is no breach of confidentiality. Consent will be implied where it is reasonable to conclude from the patient's conduct that consent has been given or that the patient makes no objection to the proposed course of action ( I Kennedy, A Grubb Medical Law, London, Butterworths, 2000 at pp 591,1085). In so far as use of patient data is justified on the basis of implied consent, it removes control of that data from patients who may in fact have no knowledge or understanding of the uses entailed. Despite this, implied consent has been relied upon to justify a wide range of uses within the NHS although there is scant legal authority for such reliance (The Protection and Use of Patient Information, London: DoH,1996; GMC Confidentiality: Protecting and Providing Information (2000) paras 7-10,16,24,29-30).

A further problem in asserting that patients control their medical records is the manner in which the concept of public interest has been used to override that control. It is a defence to an action for breach of confidentiality that disclosure is in the public interest (Attorney General v Guardian Newspapers (No 2) [1990] 1 AC 109 per Lord Goff at 282; X v Y [1988] 2 All ER 648; $W_{v}$ Egdell [1990] 1 All ER 835) which includes disclosure to prevent or report crime ( $W_{V}$ Egdell [1990] 1 All ER 835)); disclosure in the interests of justice; (A-Gv Mulholland [1963] 1 All ER 767) disclosure in the interests of free speech ( $A_{V} B$ Plc [2002] 3 WLR 542) and disclosure to prevent the risk of serious harm or death ( $W_{V}$ Egdell [1990] 1 All ER 835).

Disclosure of patient data to avert a real risk of harm to the public falls within this exception, including disclosure to regulatory bodies and to the police, for example in child abuse cases or where the competence or integrity of a healthcare professional, and so patient safety, is in issue (Woolgar v Chief Constable of the Sussex Police [1999] 3 All ER 604). In determining whether disclosure can proceed on this basis a balance must be struck between competing 
public and private interests, including the interest in the maintenance of medical confidentiality and the interest in protecting the public against risk ( $W_{V}$ Egdell [1990] 1 All ER 835 at 845-846 per Sir Stephen-Brown P, at 848 per Bingham LJ; Woolgar v Chief Constable of Sussex Police [1999] 3 All ER 604 at 615).

If a health care professional takes a decision to disclose information which is made in accordance with professional/governmental guidance, it is unlikely that a court would criticise it ( $W_{V}$ Egdell [1990] 1 All ER 835: see discussion at 851, per Bingham LJ: in assessing whether a disclosure was justified, close attention was paid to the guidance set out in the Blue Book and the doctor's professional judgment). This is significant because the most recent GMC guidance on confidentiality permits disclosures to take place for a wide range of reasons in the public interest and, as noted, on grounds of implied consent. (GMC Confidentiality: Protecting and Providing Information, 2000, paras 18-20,25-26,31,36-37.)

In addition, there are signs that the courts are increasingly willing to use a public interest justification to override patient control of medical information. For example in A Health Authority $v$ X [2001] UKHRR 1213 at least one patient objected to the release of their records in the course of an investigation into a GP's practice. The judge at first instance ruled that where documents were to be used otherwise than in the patient's best interests, such as for disciplinary or regulatory procedures, there had to be a compelling public interest in their disclosure (ibid at 1237). Furthermore as disclosure would breach a patient's Article 8 rights, any argument based upon public interest had to show that disclosure was necessary to meet the aims set out in Article 8(2), in particular public safety, the protection of health and morals and the rights and freedoms of others, and the nature and extent of the disclosure had to be a proportionate response to that aim (ibid at 1237-39). Here a compelling public interest lay in the need for the Health Authority to investigate whether the care provided by GPs was adequate so as to protect the public and individual patients (ibid at 1230-1231, 1238, applying Woolgar v Chief Constable of Sussex Police [1999] 3 All ER 604). The decision was subsequently affirmed by the Court of Appeal although the public interest was identified as being that in the proper administration of disciplinary proceedings([2002] 2 All ER 780 at 786 per Thorpe LJ).

The finding that disclosures for both regulatory and disciplinary purposes may be justifiable by reference to the public interest has unwelcome implications for patient autonomy. In the earlier case of Woolgar the adult who had opposed disclosure had been an alleged or potential wrongdoer and could be viewed as having forfeited or weakened their claim to confidentiality. The law will not preserve the secrecy of a wrongdoing ( $A G_{V}$ Guardian Newspapers Ltd (No. 2) [1990] 1 AC 109 at 268-69 per Lord Griffiths, at 282 per Lord Goff) nor will equity grant a remedy if the complainant is guilty of improper conduct
(Hubbard $v$ Vosper [1972] 2 QB 84). However in the case of $\mathrm{X}$, patient confidentiality was violated and patient ability to control the use of medical information overridden even though the patients were not connected with any wrongdoing.

A further concern is that the identification in A Health Authority ${ }_{V} X$ of the public interest with Article 8(2) requirements might weaken the domestic protection of patient confidentiality by legitimating and confirming a wide interpretation of the requirements of the public interest, to mirror the European Court's approach to Article 8(2). The level of protection afforded to patient privacy at Convention level is weak. This can be seen in particular in the case of $M S_{V} S_{w e d e n}(1999) 28$ EHRR 313 which was extensively relied on in A Health Authority $v$ X. This case indicated that decisions authorising the release of medical information for regulatory or administrative reasons are likely to be justifiable under Article 8(2) at European level.

The role of the public interest in undermining patient control of their medical records and subsequently patient privacy can be seen further in legislative developments which have legitimated a wide range of uses within the NHS and restricted the ambit of the common law.

\section{SECTION 60: AUTHORISATION AND THE HEALTH SERVICE (CONTROL OF PATIENT INFORMATION) REGULATIONS 2002}

The controversial section 60 of the Health and Social Care Act 2001 ('2001 Act') allows for regulations to be made to permit the disclosure of patient information for medical purposes (for a definition see s60(10)) without consent. This can occur where disclosure is necessary or expedient in the interests of improving patient care or in the public interest $(\mathrm{s} 60(1))$.

On 23 May 2002, The Health Service (Control of Patient Information) Regulations (SI 2002/1438: 'the Regulations') were approved by Parliament. These provide class authorisation for the disclosure of patient data without consent in three main categories of case which include disclosures to Cancer Registries, (s2) disclosures made for monitoring public health (s3) and a list of Scheduled uses which include disclosures for medical research and to carry out auditing and monitoring of the provision of health care (s5).

To safeguard patient's rights, a new body was created, the Patient Information Advisory Group ("PIAG") whose role is to represent patients' interests and to advise the Government on the use of powers under section 60 (s61) including advising the Secretary of State on whether applications under the Schedule to the Regulations and directly under section 60 of the Act should succeed (s61 of 2001 Act, s5 of the Regulations). 
The Regulations are of concern because they remove control of the use and disclosure of patient data from patients for a wide range of purposes in the name of the public interest. There is no provision for patient opt-out and although a public register will be maintained of some of the authorised uses, it will not be comprehensive. For example, it will not include information concerning disclosures to monitor public health. Patients will not therefore know who is making use of their information and for what specific purpose. Subsequently any challenge, legal or political, to such use will be difficult. In addition the legislation grants patients no remedy if their information is misused and where a use is supported by the legislation, the Regulations provide that there will be no breach of the duty of confidentiality even though patients may object to the use (s4).

The Regulations therefore restrict the scope of the law of confidentiality and reduce patient rights to control and challenge the use of personal information. It might be argued that patient privacy will be protected through PIAG. It has exercised its role reasonably robustly so far (of 11 applications for section 60 support, it has approved six. The remainder were either rejected or advised to submit revised applications: Minutes 10 December 2001, PIAG 102/2002; Minutes 8 March 2002, PIAG 202/2002: http://www.doh.gov.uk/confiden). On the other hand, PIAG has a purely advisory role. It is not clearly independent of the executive: its members are appointed not by patient groups but by the Secretary of State and it appears to have a close relationship with the Department of Health. The extent to which it will be active in protecting patient rights and patient privacy therefore remains to be seen. In addition even accepting that the introduction of PIAG is to be welcomed, it remains the case that its introduction was a legitimising part of an initiative the effect of which was to restrict patient rights by removing decisions about the control of patient information from patients.

\section{CONCLUSION}

The requirement of patient consent and the ability of patients to control the use of information which they impart in confidence to their health carer appears to have been sacrificed by both the courts and the legislature in the name of the public interest. This is of concern both because when information is disclosed without patient consent there is an infringement of patient autonomy, and because the pressures upon patient privacy are such that unless a patient's right to confidentiality is given greater protection there is a risk that patient privacy will be whittled away. It is currently too easy to argue successfully that disclosures of patient information should take place in the public interest. In the case of $R_{V}$ Department of Health ex parte Source Informatics Ltd [2001] QB 424 it was argued that the disclosure of patient data to pharmaceutical companies was in the public interest because not only did it permit the companies to target their marketing more effectively, it allowed them to keep doctors better informed of the products available (at 432). Although the court did not have to rule on this argument (it found that there had been no breach of confidentiality), it illustrates the kind of challenges posed to a weak right to confidentiality which denies patients control over personal information. In order to better protect patient privacy from such pressures, the law must place greater emphasis on the requirement of consent and patients' rights of control over the flow of confidential personal information.

\section{Joan Loughrey}

Senior Lecturer in Law, University of Central Lancashire 